\title{
A gestão do desejo dos corpos através da comunicação e mídia: um estudo panorâmico-monográfico dos periódicos da Educação Física brasileira
}

\author{
Cristiano Mezzaroba' \\ Fabio Zoboli² \\ Elder Silva Correia ${ }^{3}$
}

\section{RESUMO}

O incessante fluxo de afecções geradas pela mídia constrói corpos que refletem subjetividades que organizam ações corpóreas de relações. O presente texto objetivou analisar a produção do conhecimento da temática "corpo" ligada a pesquisas de "comunicação" e "mídia" em periódicos da Educação Física (EF) brasileira no período de 2000-2015 a fim de visualizarmos os modos como este campo de saber vem estudando as afecções midiáticas que giram em torno da temática do corpo. Caracterizou-se como um estudo qualitativo de revisão bibliográfica de cunho panorâmico-monográfico, tendo como amostra textos completos online de 12 periódicos da EF brasileira classificados como A1, A2, B1, B2, B3 e B4 pelo WebQualis da Capes. Concluímos que o corpo tratado nesses textos se apresenta como um ponto de ancoragem para a articulação de afetações e desejos, ou seja, o corpo da comunicação e da mídia é um corpo em contínua luta política.

Palavras-chave: Corpo. Comunicação. Mídia. Produção do conhecimento. Periódicos de educação física.

1 Doutor em Educação. Professor Adjunto II do Departamento de Educação Física da Universidade Federal de Sergipe (UFS). São Cristovão/Sergipe, Brasil. E-mail: cristiano_mezzaroba@yahoo.com.br

2 Doutor em Educação. Professor do Departamento de Educação Física da Universidade Federal de Sergipe (UFS). São Cristovão/Sergipe, Brasil. E-mail: zobolito@gmail.com

3 Mestre em Educação Física. Universidade Federal do Espírito Santo (UFES). Vitória/Espírito Santo, Brasil. E-mail: eldercorreia21@gmail.com

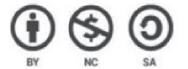

Este texto está publicado sob uma licenca Creative Commons Atribuição NãoComercial-Compartilhalgual - CC BY NC AS

Mais detalhes em: https://br.creativecommons.org/licencas/ 
The management of the desire of the bodies through communication and media: a panoramic-monographic study of the brazilian journals of Physical Education

\begin{abstract}
The incessant flow of affections generated by the media constructs bodies that reflect subjectivities that organize corporeal actions of relations. This study aimed at analyzing the production of knowledge about the topic "body" linked to "communication" and "media" research in the Brazilian Journals of Physical Education (PE) in the period between the years of 2000 and 2015 in order to visualize the ways in which this field of knowledge has been studying the mediatic affections that revolve around the theme of the body. It was characterized as a qualitative study of a bibliographic review with a panoramic-monographic nature, having as a sample complete online texts of 12 Brazilian Journals of PE classified as A1, A2, B1, B2, B3 and B4 by Capes'WebQualis. We concluded that the body addressed in these texts presents itself as an anchorage point for the articulation of affectations and desires, that is, the body of communication and media is a body in continuous political struggle.
\end{abstract}

Keywords: Body. Communication. Media. Knowledge production. Journal of physical education.

La gestión del deseo de los cuerpos a través de la comunicación y medios de comunicación: un estudio panorámico-monográfico de los periódicos de la Educación Física brasileña

\title{
RESUMEN
}

El incesante flujo de afecciones generadas por los medios de comunicación construuye cuerpos que reflejan subjetividades que organizan acciones corpóreas de relaciones. Este estudio tuvo como objetivo analizar la producción del conocimiento de la temática "cuerpo" vinculada a investigaciones de"comunicación" y "medios" en periódicos de la Educación Física (EF) brasileña, en el período 2000-2015 con el fin de visualizar las maneras cómo este campo de saber viene estudiando las afecciones mediáticas que giran alrededor de la temática del cuerpo. Se caracteriza por ser un estudio cualitativo de revisión bibliográfica de naturaleza panorámica-monográfica, con una muestra de textos completos en línea de 12 periódicos de la EF brasileña clasificados como A1, A2, B1, B2, B3 y B4 por WebQualis de la Capes. Llegamos a la conclusión de que el cuerpo tratado en estos textos se presenta como un punto de anclaje para la articulación de afecciones y deseos, es decir, el cuerpo de la comunicación y los medios de comunicación es un cuerpo en lucha política continua.

Palabras clave: Cuerpo. Comunicación. Medios de comunicación; Producción de conocimiento. Periódicos de la educación física. 


\section{INTRODUÇÃO' ${ }^{4}$}

Em polêmico livro intitulado de “O Anti-Édipo", Deleuze e Guattari (1996) desenvolvem uma série de críticas à psicanálise, principalmente acerca das noções de inconsciente e desejo. Para os autores, o desejo não é falta, ele não é carente de um objeto exterior a ele. Inspirados em Spinoza, eles concebem o desejo como o esforço ou inclinação por algo que seja útil ao próprio desejo, por isso, nesta perspectiva, segundo Deleuze (2002) não desejamos algo porque ele é bom, mas ele é bom porque o desejamos. O desejo é produção do real, em que fundamentalmente a produção social é antes de tudo produção desejante. Para Silva (2013) o que está em jogo nos agenciamentos (relações) desejantes é a captação de forças, a produção de vibrações intensivas no encontro entre os elementos participantes, é o homem que busca apropriar-se da potência de alguma coisa.

Assim, o desejo de um sujeito não é fechado em si mesmo, nem estagnado, mas modificado a partir dos encontros que esse sujeito faz. Neste sentido, podemos compreender que fundamentalmente o processo de subjetivação ${ }^{5}$ presente na sociedade ocorre através de como o desejo é produzido/circulado. Sob este aspecto, Safatle (2016) destaca que é preciso partir da compreensão de que "sociedades" em seu nível mais fundamental são circuitos de afectos e, o que fazem os sujeitos aderirem a determinados modos de vida, maneiras de pensar e se comportar ocorrem a partir da produção e circulação de determinados afectos. Isso acontece na medida em que determinadas formas de subjetivação estão fundamentadas em certos afectos que tornam possível a continuação e repetição dessas mesmas maneiras de subjetivar.

Isso significa que os processos de subjetivação são inseparáveis da forma com que os sujeitos são afetados, isto é, produzir subjetividades se refere à capacidade de ser afetado, de entrar em um regime de afecção ${ }^{6}$ que sustenta certas práticas sociais, comportamentos, maneiras de pensar e agir, de gostar ou não de alguma coisa. É devido a esse regime de afecções que "[...] nem todas as corporeidades são idênticas; algumas são unidades imaginárias, outras são articulações simbólicas, outras são dissociações reais. Cada regime de corporeidade tem seu modo de afecção" (SAFATLE, 2016, p. 20).

Assim, os processos de subjetivação se dão necessariamente a partir das afecções corporais, já que é necessário o sujeito ser afetado para que possa produzir determinados modos de vida. O incessante fluxo de afecções constrói corpos que refletem subjetividades e que organizam ações corpóreas, isto é, legitimam determinados modos de sentir, pensar

4 Os autores declaram não haver nenhum tipo de conflito de interesse.

5 O sentido do processo de subjetivação aqui, está pautado na concepção de que o mesmo se dá através da gestão do desejo. Se o desejo é a inclinação por algo, o processo de subjetivação é o meio pelo qual tal desejo é legitimado pelo próprio sujeito, isto é, tal inclinação é legitimada pela própria subjetividade. Por exemplo, as práticas sociais das quais um sujeito faz parte, devem ser antes de tudo legitimadas via processo de subjetivação para que este sujeito crie um vínculo com as mesmas, para que elas lhes façam sentido.

6 O regime de afecção deriva da relação do corpo do sujeito com o mundo. Dado um encontro, nesse corpo serão produzidos determinados efeitos. Esses efeitos são o que Spinoza e Deleuze chamam de "afecções". Por exemplo, para ouvir uma música, o sujeito deve ser afetado por ela, é necessário que o seu aparelho auditivo capte as ondas sonoras da música. O ato de ouvir é o efeito da relação entre o corpo do sujeito e as ondas sonoras. 
e agir. Neste sentido entendemos o "corpo" neste artigo a partir de uma perspectiva deleuzeana como uma força - ou uma conjunção de forças - dotada de capacidades de afetar e ser afetada. "Uma força ou um corpo é ativo e afirmativo quando ele não somente procura se preservar e se capitalizar, mas também gasta e atualiza sua capacidade ao máximo, indo ao limite do que pode fazer" (SHAVIRO, 2015, p. 76).

Deleuze (2002), baseado em Spinoza, não define o corpo a partir de uma forma, seus órgãos ou suas funções, mas por relações de repouso e movimento, velocidades e lentidões, bem como o poder que um corpo tem de afetar e ser afetado (afeto compreendido como variação da potência, no sentido espinosano), ou seja, seriam as proposições cinéticas e dinâmicas de corpo, este que está num plano de imanência - um plano de composição, produção. Há aqui uma definição de corpo intensivo, baseado nas forças e potências que o constitui na medida em que o corpo é um modo de efetuação/expressão de nossa potência.

Na contemporaneidade, uma das estruturas que mais produz regimes de afecções e, consequentemente, modos de subjetivação ${ }^{7}$, é a cultura midiática ${ }^{8}$. Seja pela sua diversidade, seja pela sua intensidade, bem como, também, pela sua onipresença em nosso cotidiano, as mídias são fortes gestoras de nossos desejos e da circulação de afectos. As mídias convidam - ou forçam - meu corpo a se confrontar com um fluxo de sensações que não posso relacionar a uma presença física nem traduzir a uma abstração sistemática (SHAVIRO, 2015).

Seja na promoção de um comportamento de gênero; na gestão do desejo de um corpo belo; na compra de um produto alimentício; ou, um modo de ver e experimentar um esporte ou uma "dança da moda", o que a cultura midiática promove é a circulação de determinados modos de afecção que gerenciam o desejo, produzindo sujeitos com determinado gosto, percepção e comportamento. Gostaríamos aqui de enfatizar que essa produção de subjetividades ocorre necessariamente pelo processo de incorporação, isto é, produzir sujeitos para o consumo ou para a busca de um padrão de beleza, por exemplo, está inseparável da produção de um corpo que deseje isso - por isso precisa de um determinado circuito de afectos que sustente esse desejo. Significa dizer que a mídia opera através de uma experiência afectiva, ela envolve os sujeitos no plano da sensibilidade, da experiência via corpo e desejo. A gestão do corpo e do desejo para um determinado fim (como a necessidade de consumir algo) por meio do circuito de afectos que o atravessam é fruto de uma determinada pedagogia que constitui a experiência afectiva diante da limitação

7 Há de se distinguir o que são processos de subjetivação e modos de subjetivação. O primeiro, diz respeito aos meios pelos quais as subjetividades são construídas, e a segunda são as próprias subjetividades em suas singularidades. No entanto, apesar de serem diferentes, ambos estão em uma relação de imanência na qual é impossível pensar um sem o outro, na medida em que o processo de subjetivação pressupõe uma implicação do sujeito para tal.

8 A cultura midiática se configura na maneira moderna e atual que presenciamos (e experenciamos) com a presença intensa e onipresente dos mais diversos veículos de comunicação - jornais, revistas, rádio, cinema, televisão, redes sociais, portais digitais, internet em geral - e seu indubitável modo peculiar e persuasivo em pautar seus temas, realizar suas mediações e concretizar seus objetivos e intencionalidades, sejam elas implícitas ou explícitas. 
do desejo. Por isso, certas lógicas de subjetivação, como o de um padrão de beleza, se sustentam pela construção de um desejo que gera uma afecção de necessidade, como se o único objeto que ampliasse tal desejo fosse aquele padrão de beleza idealizado. Nunca tivemos, na história humana, tanta coisa para consumirmos, para usarmos, comprarmos, acoplarmos (por dentro e por fora) de nossos corpos!

É neste sentido que a relação entre corpo, mídia e comunicação acontece. O corpo aqui é entendido a partir de uma perspectiva deleuzeana - pautada em Spinoza - conforme descrito acima, no entanto, é importante ainda mencionar que a compreensão do:

[...] que é o corpo não pode estar descontextualizada da contingência de sua produção, razão pela qual afirmamos que a Educação Física não estuda corpos, mas sim práticas que tomam por objeto esses corpos em suas práticas, o que implica necessariamente interpretá-lo como plural (GALAK et al., 2017, p.14, tradução nossa).

A comunicação, conforme Thompson (1998), é caracterizada como um tipo distinto de atividade social que envolve a produção, a transmissão e a recepção de formas simbólicas e implica a utilização de recursos de vários tipos. Já a mídia seria esse conjunto de meios de comunicação humana que se realiza via algum aparato técnico, mas também como uma "indústria midiática" que produz e veicula símbolos e significados que compartilhamos contemporaneamente (BETTI; PIRES, 2005). Se a cultura midiática trabalha com informações, imagens, sons e discursos, ela age necessariamente naquilo que segundo Safatle (2016) nos conduz a aderir um determinado comportamento: regimes de afecção de modo a gerir o desejo.

Assim, existem produções na EF (prática pedagógica que se volta para o corpo e o movimento) que buscaram compreender como se dá a relação entre corpo, mídia e comunicação no âmbito deste campo do conhecimento. Neste sentido, o presente artigo objetivou identificar e analisar a produção do conhecimento da temática "corpo" ligadas a pesquisas de "comunicação" e "mídia" em periódicos da EF brasileira, entre 2000-2015, a fim de visualizarmos os modos como a EF vem estudando as afecções midiáticas que giram em torno da temática do corpo.

Para tanto, dividimos o texto em 3 partes: (1) descrevemos a metodologia que estruturou esta pesquisa; (2) apresentamos os dados para estabelecer um diálogo teórico, interpretando-os para visualizar os modos como a EF vem estudando as afecções midiáticas e corpo; (3) tecemos nossas considerações finais acenando possibilidades para a EF frente aos regimes de afecções produzidas pela cultura midiática.

\section{Procedimentos metodológicos}

Este texto é fruto de uma parceria de dois grupos de pesquisas da Universidade Federal de Sergipe que trabalham com a temática da comunicação: "Labomídia" e "Corpo e política". O grupo Labomídia se organiza, na esfera de suas atividades, em três linhas 
de pesquisas: Análises de produtos da mídia; Estudos dos meios e processos midiáticos; e, Mídia-Educação. O grupo de pesquisa: "Corpo e política", possui também três linhas de pesquisas: Corpo e Epistemologia; Corpo e Educação; e, Corpo e Comunicação. Esta última, em específico, tem como objetivo estudar as mídias como ferramenta cultural e política para a governabilidade do corpo e seus comportamentos sociais: texto, pintura, fotografia, cinema, televisão, rádio, internet, mídias impressas (jornais, revistas, livros etc.) e mídias digitais.

Este estudo se caracteriza como sendo uma investigação de revisão bibliográfica. Para Lakatos e Marconi (1992, p. 43-44) este tipo de pesquisa parte:

Do levantamento de toda bibliografia já publicada em forma de livros, revistas, publicações avulsas e impressa escrita. Sua finalidade é colocar o pesquisador em contado direto com tudo aquilo que foi escrito sobre determinado assunto, com o objetivo de permitir ao cientista o reforço paralelo na análise de suas pesquisas ou manipulações de suas informações.

Por se tratar de um estudo de revisão bibliográfica não possuímos controle sobre as variações temáticas a serem reveladas dentro de um corpus específico de fontes; o que por consequência, vai dar um panorama do tema em um dado contexto específico ou especializado de fontes. Assim, o texto é também de caráter panorâmico-monográfico sobre a literatura, pois como menciona Eco (1995), o estudo panorâmico lida com temáticas variantes de temas amplos no que tange ao seu contexto sem restrição de campo. Entendemos que ao recortar os limites das fontes o estudo perde um pouco sua conotação panorâmica e passa a ser monográfico - monográfico no sentido de se deter a um único tema. Isso acontece no presente estudo na medida em que elegemos o "corpo" nas produções de EF nos estudos dentre de um tema maior: "comunicação e mídia". No entanto ele retoma sua característica panorâmica na medida em que não fazemos vários estudos monográficos sobre inúmeros temas que existem dentro do tema geral, ou seja, ao tratar dos dados empíricos encontrados no recorte "corpo" visualizamos variantes temáticas dentro desse recorte e então retomamos a abordagem panorâmica do estudo pela impossibilidade de aprofundamento de cada um dos temas. Assim, entendemos as temáticas encontradas como aquelas que se diversificam dentro do tema geral. Que por ser geral acaba sendo panorâmico, pois a tendência é lidar com pequenos componentes temáticos que constituem o geral.

A amostra eleita para nosso estudo foram os textos completos de doze periódicos da EF brasileira (conforme Quadro 01) avaliados pelo Qualis periódicos da $\mathrm{CAPES}^{9} \mathrm{com}$ o conceito A1, A2, B1, B2, B3 e B4: Movimento/UFRGS, Motriz/SP, Revista Brasileira de Ciências do Esporte/CBCE, Revista Brasileira de EF e Esporte/USP, Revista de EF da UEM, Licere/UFMG, Motrivivência/UFSC, Pensar a Prática/UEG, Revista Brasileira de Atividade Física e Saúde, Revista Brasileira de Ciência e Movimento/UCB, Revista Mackenzie de EF e Esporte e Kinesis/UFSM.

9 Este é o parâmetro "Qualis 2014" obtido em 19 de setembro de 2016 na plataforma Sucupira: <sucupira. capes.gov.br>. 
Num primeiro momento o levantamento dos dados empíricos foi realizado no banco de dados dos periódicos utilizando a ferramenta de busca disponível online, selecionando o filtro "título" para aplicar os seguintes termos de busca: "mídia", "midiático", "comunicação", "televisão", "revista", "jornal", "portal”, "cinema", "filme”, , jogos virtuais", "jogos eletrônicos", "blog", "rádio", "rede social", e "internet".

Em etapa posterior, fizemos a leitura dos resumos dos textos encontrados e excluímos os resumos em que as palavras "corpo" ou "corpos" não apareciam. Ainda a fim de refinar a nossa amostra, efetivamos algumas exclusões conforme os seguintes critérios: a) textos de anais de eventos; b) textos apresentados como resumos; c) resenhas; d) textos que extrapolavam o recorte temporal de 2000-2015; e) textos em que no resumo as palavras "corpo" e "comunicação" tinham um sentido diferente ao proposto na pesquisa; f) textos buscados com a palavra "revista" que faziam alusão a apresentações editoriais.

\section{Análise e discussão}

Como descrito na metodologia, primeiramente fizemos um levantamento dos textos de acordo com nosso objeto de investigação, ou seja, a partir do filtro "título", as alusões aos termos "mídia" e "comunicação", nos 12 periódicos citados. Essa busca acarretou 207 textos. Após a leitura destes, excluímos aqueles em que as palavras "corpo" ou "corpos" não apareciam, resultando um total de 18 textos selecionados, conforme podemos observar no Quadro 01.

Quadro 01 - Quantitativo de textos por periódico

\begin{tabular}{|l|c|c|}
\hline Revista & Total de textos & Total temática “corpo" \\
\hline motrivivência & 46 & 5 \\
\hline Movimento & 41 & 4 \\
\hline Pensar a Prática & 22 & 4 \\
\hline Licere & 15 & 2 \\
\hline Brasileira de Atividade Física e Saúde & 15 & 0 \\
\hline Ciência e Movimento & 14 & 0 \\
\hline RBEFE/ USP & 12 & 1 \\
\hline Kinesis & 11 & 0 \\
\hline RBCE & 11 & 0 \\
\hline Motriz & 10 & 0 \\
\hline Mackenzie & 5 & 1 \\
\hline UEM & 5 & 1 \\
\hline TOTAL & $\mathbf{2 0 7}$ & $\mathbf{1 8}$ \\
\hline
\end{tabular}

Fonte: os autores 
Visualizamos, aqui, que boa parte da produção identificada, conforme os parâmetros já informados, está publicada em duas revistas - Motrivivência e Movimento - que se posicionam como periódicos de caráter eminentemente sociocultural, o que permite supor um entendimento sob o viés das humanidades quando o objeto em questão é o "corpo". No quadro 02 temos um panorama da produção encontrada.

Quadro 02 - Textos com título, autoria, periódico e ano.

\begin{tabular}{|c|c|}
\hline Título & Periódico/Ano \\
\hline $\begin{array}{l}\text { Beleza e feminilidade: o corpo feminino nas páginas da Revista Vida } \\
\text { Capichaba (1925-1939) } \\
\text { (SILVA; GOMES; ALMEIDA) }\end{array}$ & $\begin{array}{l}\text { Motrivivência } \\
2015\end{array}$ \\
\hline $\begin{array}{l}\text { Construindo diálogos entre a mídia-educação e a EF: uma experiência } \\
\text { na escola } \\
\text { (CHAVES et al) }\end{array}$ & $\begin{array}{l}\text { Motrivivência } \\
2015\end{array}$ \\
\hline $\begin{array}{l}\text { Identidade(s) feminina(s) e cuidado de si na Revista AG } \\
\text { (PINTO et al) }\end{array}$ & $\begin{array}{l}\text { Motrivivência } \\
2012\end{array}$ \\
\hline $\begin{array}{l}\text { Cultura corporal na pauta do jornal: notas de uma análise a partir do } \\
\text { "Programa AN Escola" } \\
\text { (SOUZA) }\end{array}$ & $\begin{array}{l}\text { Motrivivência } \\
2010\end{array}$ \\
\hline $\begin{array}{l}\text { Corpo e gênero: a Revista Capricho e a produção de corpos femininos } \\
\text { (GOELLNER; FIGUEIRA) }\end{array}$ & $\begin{array}{l}\text { Motrivivência } \\
2002\end{array}$ \\
\hline $\begin{array}{l}\text { Corpo e educação no escotismo a partir da Revista } \\
\text { O Tico Tico (1921-1933) } \\
\text { (HEROLD JUNIOR) }\end{array}$ & $\begin{array}{l}\text { Movimento } \\
2015\end{array}$ \\
\hline $\begin{array}{l}\text { Corpos femininos volumosos e estética: discursos } \\
\text { contra-hegemônicos sobre beleza em blogs na internet } \\
\text { (GODOI) }\end{array}$ & $\begin{array}{l}\text { Movimento } \\
2011\end{array}$ \\
\hline $\begin{array}{l}\text { Culto ao corpo e exposição de produtos na mídia especializada em } \\
\text { estética e saúde } \\
\text { (OLIVEIRA et al) }\end{array}$ & $\begin{array}{l}\text { Movimento } \\
2010\end{array}$ \\
\hline $\begin{array}{l}\text { O corpo e as técnicas para o embelezamento feminino: esquemas da } \\
\text { indústria cultural na Revista Boa Forma } \\
\text { (ALBINO; VAZ) }\end{array}$ & $\begin{array}{l}\text { Movimento } \\
2008\end{array}$ \\
\hline $\begin{array}{l}\text { A concepção de obesidade e padrão corporal por mediações } \\
\text { ideológicas da mídia } \\
\text { (VENDRUSCOLO; MALINA; AZEVEDO) }\end{array}$ & $\begin{array}{l}\text { Revista Pensar a } \\
\text { Prática } \\
2014\end{array}$ \\
\hline $\begin{array}{l}\text { A Revista Vida e Saúde: modos de olhar e educar o corpo feminino em } \\
\text { suas páginas (1940-1950) } \\
\text { (DALBEN; SOARES) }\end{array}$ & $\begin{array}{l}\text { Revista Pensar a } \\
\text { Prática } \\
2008 \\
\end{array}$ \\
\hline $\begin{array}{l}\text { EF e televisão: reflexões sobre sensibilidade, tecnologia e conhecimento } \\
\text { (ARAÚJO; PORPINO) }\end{array}$ & $\begin{array}{l}\text { Pensar a Prática } \\
2007\end{array}$ \\
\hline $\begin{array}{l}\text { A experiência de ver filmes na formação inicial de professores de EF } \\
\text { (PINTO; PEREIRA) }\end{array}$ & $\begin{array}{l}\text { Pensar a Prática } \\
2005\end{array}$ \\
\hline
\end{tabular}




\begin{tabular}{|l|l|}
\hline Título & Periódico/Ano \\
\hline $\begin{array}{l}\text { Os “avatares" do corpo rascunho: experiência de jovens universitários } \\
\text { nas redes sociais } \\
\text { (JUBÉ; ALMEIDA; FERES NETO) }\end{array}$ & $\begin{array}{l}\text { Licere } \\
2014\end{array}$ \\
\hline $\begin{array}{l}\text { Corpo joystick: } \\
\text { cinema, videogames e estilo de vida ativo } \\
\text { (FINCO; FRAGA) }\end{array}$ & $\begin{array}{l}\text { Licere } \\
2013\end{array}$ \\
\hline $\begin{array}{l}\text { Educação do corpo feminino: um estudo na Revista Brasileira de EF } \\
\text { (1944-1950) } \\
\text { (MORAES E SILVA; FONTOURA) }\end{array}$ & $\begin{array}{l}\text { RBEFE } \\
2011\end{array}$ \\
\hline $\begin{array}{l}\text { A Educação Física e o adolescente: a imagem corporal e a estética da } \\
\text { transformação na mídia impressa } \\
\text { (MALDONADO) }\end{array}$ & $\begin{array}{l}\text { Mackenzie } \\
2006\end{array}$ \\
\hline $\begin{array}{l}\text { Representação do corpo feminino na Revista Claudia no ano de 2006: } \\
\text { retrato de uma produção restrita } \\
\text { (SALVINI; MISKYW) }\end{array}$ & $\begin{array}{l}\text { Revista da UEM } \\
2008\end{array}$ \\
\hline
\end{tabular}

Fonte: os autores

Analisando o conjunto de textos selecionados, é possível identificar que o corpo feminino predomina nessas produções (SILVA; GOMES; ALMEIDA, 2015; GOELLNER; FIGUEIRA, 2002; OLIVEIRA et al, 2010; ALBINO; VAZ, 2008; DALBEN; SOARES, 2008; SALVINI; MISKYW, 2008; PINTO et al, 2012; MORAES E SILVA; FONTOURA, 2011), o que reforça a ideia de que o corpo feminino é aquele que, hegemonicamente, aparece e é "consumido" midiaticamente, é o corpo que é mais comunicável, podemos inferir que seja tanto no sentido de chamar atenção das mulheres quanto de ser desejado pelo público masculino. Percebe-se, no conjunto das produções analisadas, a intencionalidade de criação de feminilidades, que ao longo dos períodos históricos vão sendo transformadas, mas estão sempre presentes, "querendo" algo das mulheres que ainda lhes faltam. Como exemplo, trazemos os apontamentos de Pinto et al (2012, p.122), que, ao analisar o conteúdo de um suplemento de um jornal capixaba, consideram que "A gramática das reportagens utiliza um vocabulário imperativo, sempre sugerindo o que a mulher deve ou não fazer, deixando claras opções para se conquistar a boa forma ideal para o seu corpo."

O quadro 03 apresenta os veículos midiáticos que pautaram os estudos analisados.

Visualiza-se, a partir do Quadro 03, que há uma diversidade de maneiras pelas quais o corpo é "capturado" enquanto discurso, imagem e publicidade. No caso dos 18 textos selecionados, percebemos a predominância de pesquisas que se utilizam de veículos impressos (SILVA; GOMES; ALMEIDA, 2015; GOELLNER; FIGUEIRA, 2002; HEROLD JUNIOR, 2015; ALBINO; VAZ, 2008; OLIVEIRA et al, 2010; VENDRUSCOLO; MALINA; AZEVEDO, 2014; DALBEN; SOARES, 2008; MALDONADO, 2006; SALVINI; MISKYW 2008; PINTO et al, 2012; SOUZA, 2010), primeiro, porque são veículos que se apresentam como manuseio mais fácil, ou seja, para coletar e tratar os dados. Diferentemente do que ocorre em relação à televisão, que demanda um trabalho e esforço (por vezes técnico) em 
capturar, gravar, editar e manipular o material que se pretende observar/analisar; ou mesmo uma rede social, que, com o tempo, pode deixar de existir (como no caso do próprio Orkut); ou mesmo um site ou blog da internet, que pode "sair do ar" ou ser modificado.

Quadro 03 - Indicativo dos veículos midiáticos.

\begin{tabular}{|c|c|}
\hline Veículo investigado & Quantitativo \\
\hline Revistas impressas & 9 \\
\hline Jornais impressos & 2 \\
\hline Televisão & 1 \\
\hline Blogs & 1 \\
\hline Cinema & 1 \\
\hline Videogames & 1 \\
\hline Redes sociais & 1 \\
\hline Periódico científico & 1 \\
\hline Diverso & 1 \\
\hline
\end{tabular}

Fonte: os autores

Se tal inferência for realizada a partir da materialidade de uma determinada época recente, podemos considerar que com o advento e intensificação das mídias digitais o que visualizamos, atualmente, é que se deter aos veículos impressos era uma maneira mais segura e garantida de obter, reservar e manusear os dados - e hoje as mídias digitais (como os estudos de GODOI, 2011 e JUBÉ; ALMEIDA e FERES NETO, 2014) e o acesso mais facilitado e até popularizado que temos nos permitem ampliar essas possibilidades de investigação a partir do que veiculam as diversas mídias.

A Revista Boa Forma se apresentou como aquela que mereceu destaque por parte da observação dos pesquisadores brasileiros, explicitamente nos estudos de Oliveira et al (2010), que observou a relação das reportagens com a publicidade veiculada, o papel dos especialistas para legitimar a informação, a renegação da profissão de professor de Educação Física, a exposição das imagens e culto ao corpo atrelado a elas, a ênfase nos corpos brancos e femininos e a culpabilização da mulher; de Albino e Vaz (2008), que desvelam como ocorre um "dever ser" feminino na revista supracitada; e de Maldonado (2006), que comprovou a formatação de um padrão de beleza corporal feminino.

É possível identificar elementos que indicam que a mídia realiza uma "pedagogia cultural" (CHAVES et al, 2015; MORAES E SILVA; FONTOURA, 2011; PINTO et al, 2012; SALVINI; MISKYW, 2008; OLIVEIRA et al, 2010) em relação ao corpo e à saúde, sendo que as tecnologias (e seus discursos) se colocam como dispositivos que afetam subjetividades, como a pesquisa de Oliveira et al. (2010), que utilizando-se dos referenciais dos estudos culturais (Foucault e Derrida) e em autores que abordam a história do corpo, discutem como ocorre a construção de discursos sobre corpo e identidade feminina, denunciando 
a realização de uma "pedagogia cultural" nessa produção e circulação de sentidos sobre saúde, beleza e moda, endereçando-se às meninas adolescentes e "dizendo" como deve ser o corpo jovem, moderno, saudável e feminino.

Por outro lado, apesar de serem identificadas em pequeno número, encontram-se pesquisas em que há denúncia da construção e circulação de padrões corporais nos veículos investigados, atrelados à indústria do consumo, como por exemplo, a publicação de Godoi (2011), Araújo e Porpino (2007), Chaves et al. (2015) e Jubé, Almeida e Feres Neto (2014). Especialmente em Godoi (2011, p.168), que se propôs a relatar um estudo realizado em onze blogs da internet, entre dezembro/2009 a janeiro/2010, é possível afirmar que os blogs trazem discursos contra-hegemônicos quanto ao padrão estético corporal: "[...] são espaços importantes de resistência, diálogo, debates, questionamento, disputas de significados e fortalecimento do grupo de mulheres e homens que apreciam uma forma diferente de ser bela".

Um outro aspecto a ser considerado é o fato de os veículos investigados apontarem, com frequência, que a obesidade é aquilo que deve ser combatido, reafirmando valores da magreza e da juventude/jovialidade como algo que precisam ser sempre enfatizados/ valorizados, como por exemplo, as publicações de Vendruscolo, Malina e Azevedo (2014), Maldonado (2006) e Oliveira et al. (2010). Conforme Vendruscolo, Malina e Azevedo (2014), que investigaram o discurso ideológico presente em reportagens e imagens veiculadas pela Revista Veja em oito edições aleatórias de 2010, os resultados indicam que a mídia influencia na concepção da obesidade e padrão corporal, responsabilizando os sujeitos pelos seus comportamentos e confundindo saúde, beleza e lucro.

Quanto às questões conceituais, percebe-se que o conceito de indústria cultural, formulado pelos filósofos alemães Theodor W. Adorno e Max Horkheimer, embora sem ser problematizado, costuma ser recorrente nas produções analisadas, como é o caso das pesquisas de Albino e Vaz (2008), Pinto e Pereira (2005) e Maldonado (2006). O artigo de Pinto e Pereira (2005) tem como base teórica a Teoria Crítica, com o conceito de indústria cultural, e buscou tratar, técnica e teoricamente, o uso didático do cinema nas aulas de Educação Física e na formação inicial dos professores. Na avaliação quanto à experiência realizada, tais autores consideram que, quando utilizada "a linguagem cinematográfica enquanto conteúdo, precisamos ter em mãos uma teoria estética que nos possibilite realizar análises filmísticas que tematizem o 'corpo' e a educação deste." (Idem, p.112).

De maneira geral, essa produção identificada ajuda no desvelamento quanto aos modos de endereçamento da mídia em suas formas comunicacionais, bem como, traz elementos que permitem uma imersão mais aprofundada quanto a uma educação estética (que situe corpo, sensibilidade, conhecimento, mídia, tecnologias e comunicação), perceptível nos estudos de Finco e Fraga (2013), Salvini e Miskyw (2008), Araújo e Porpino (2007), entre outros. Exemplificamos, aqui, a publicação de Finco e Fraga (2013), que se detiveram à discussão do processo de inserção do videogame na cultura contemporânea e relações com as interações humanas, principalmente quanto às características dos exergames, jogos eletrônicos para se movimentar/exercitar, e como exemplo disso, o jogo Wii Fit da Nintendo. Os autores também apresentam as possibilidades, nesse mercado dos produtos 
para a vida ativa, quanto ao Wii Fit, voltados a um público não mais infantil/adolescente, e sim adulto, preocupado com atividades corporais que "promovem" saúde.

Também podemos considerar, em relação aos aspectos técnicos das produções identificadas e analisadas, que as abordagens do tipo qualitativas são predominantes, com bastante uso de análise de conteúdo e também análise de discurso. Apenas um dos artigos referiu-se como também "quantitativo", enquanto etapa inicial do levantamento e análise dos dados. Há uma coerência entre os tipos de estudo e abordagem em realizar as investigações, com bastante presença dos estudos culturais, pós-estruturalistas, fenomenológicos e estruturalistas.

Considerando que, por se tratar de um levantamento bibliográfico, temporal e espacialmente delimitado, a partir das questões que relacionam corpo, mídia e comunicação, o que podemos inferir são apontamentos quanto à produção selecionada, e, nesse sentido, constatamos que esse corpo inserido nas narrativas midiáticas - nas suas mais variadas manifestações - é um vetor de sentido, no interior de certa estrutura sintática [ou gramática], em relação a outros corpos, que também são vetores semânticos da composição; de modo que o corpo nas mídias se expressa retratado em dinâmicas de estabilização [ortodoxas] quanto de dinâmicas de desestabilização [heterodoxas] dos modelos [protótipos, paradigmas, arquétipos] de relação de poder no interior da sociedade e suas configurações políticas [sociais, culturais, econômicas, estéticas] cada vez mais conflitivas [contraditórias, incongruentes, colidentes].

Desta forma, o corpo representado/veiculado pelas mais variadas mídias - no estudo panorâmico é possível constatar isso, principalmente pelas mídias impressas - se funde ao "meu" como que por um processo de alteridade, pois quando ele me atravessa já não o posso nem incorporar e nem expelir, não tenho escolha, sou simplesmente afectado - ou seja, ele não me deixa ileso, sou sempre de alguma forma afectado por ele: "Ele estimula e afeta meu próprio corpo, mesmo quando abole as distâncias entre meu corpo e outros corpos. Fronteiras e contornos dissolvem-se; a representação dá lugar a um contato efetivamente violento mais que imediato e não conceituável" (SHAVIRO, 2015, p.298). Alguma consequência e/ou implicação daquela forma discursiva - pelo texto que oferece uma "poção mágica", pela imagem que provoca/estimula um "adaptar-se corporal", geralmente relacionado a consumo de determinados produtos diets, lights, orgânicos, naturais, saudáveis, ou mesmo a práticas corporais diversas imbrincadas também com o consumo de certos implementos, e também com sugestões de intervenções (bio)médicas - inegavelmente afeta cada um e ao mesmo tempo o todo.

Podemos exemplificar isso a partir de Shaviro (2015), que, ao abordar o corpo cinemático, trata da dimensão da afetação do corpo pela narrativa fílmica, afetação esta que podemos amplificar para um corpo da mídia, pois ela traduz bem esses jogos de agenciamento de desejo que o corpo sofre frente aos meios de comunicação: "[...] o corpo cinemático ambivalente não é um objeto de representação, mas uma zona de intensidade afetiva, um ponto de ancoragem para a articulação de paixões e desejos, uma área de contínua luta política" (Idem, p. 307). 
No campo da arte os estudiosos de imagem se apropriaram muito das teorias do filósofo francês Henri Bergson, quando o mesmo trata da relação entre consciência e mundo. A teoria bergnosiana da imagem tenta mostrar que não há dualidade entre imagem e coisa - como se a imagem fosse produto de nossa consciência produzido pelas coisas - porém, o centro que dá sentido as todas essas imagens é o corpo:

\begin{abstract}
Meu corpo é, portanto, no conjunto do mundo material, uma imagem que atua sobre outras imagens, recebendo e devolvendo movimento, com a única diferença, talvez de que meu corpo parece escolher, em certa medida, a maneira de devolver o que recebe... Pode-se dizer que o meu corpo é matéria ou que ele é imagem, pouco importa a palavra. Se é matéria, ele faz parte do mundo material, consequentemente, existe em torno dele o fora dele. Se é imagem, essa imagem só poderá oferecer o que tiver posto nela, e já que ela é, por hipótese, a imagem de meu corpo apenas, seria absurdo querer extrair daí a imagem de todo o universo. (BERGSON, 1990, p. 11)
\end{abstract}

Para pensar os regimes de afecções da mídia em relação ao corpo é importante pensarmos sobre essa relação de consciência e mundo através da imagem organizada por Bergson. Pautado em Bergson, Fatorelli (2013) menciona que diferentemente da percepção, que mede o poder refletor do corpo, a afecção mede seu poder absorvente, aponta para o exterior do corpo, para o que esse corpo acrescenta aos corpos exteriores. Portanto, mais que prolongar estímulos externos em ações consecutivas, além de apenas reagir de modo previsível em concordância com os hábitos e com as demandas imediatas propostas pelos produtos midiáticos, o centro de intermediação pode produzir uma experiência singular, criar novos hábitos, despertar novas disposições (FATORELLI, 2013). Desta forma, a análise e discussão de produtos midiáticos pode e precisa ser pensada como um campo de intervenção pedagógica no âmbito das aulas de EF no ambiente escolar - certamente ampliando para a complexidade que outras mídias, mais utilizadas por adolescentes e jovens, vêm trazendo quando veiculam/publicizam/informam sobre as questões do "corpo" na contemporaneidade (as pesquisas atuais certamente apontarão para questões que se intensificarão em relação ao panorama elaborado até aqui, que, dos 18 textos encontrados, 11 trabalharam/desvelaram mecanismos da mídia impressa.

A guisa de fechamento pode-se considerar que as produções da EF nos dão pistas de que a relação do corpo com a cultura midiática se passa necessariamente por regimes de afecções (via consumo de imagens e discursos) que geram o desejo a ponto de, por exemplo, ter a intenção de criar determinadas formas de feminilidade; a circulação e sustentação de padrões corporais ligados à necessidade de consumo de certos produtos; ou então a valoração da magreza e juventude em detrimento da obesidade. E isso não está separado das subjetividades criadas a partir destes regimes de afecções, já que são estas subjetividades que vão sustentar e legitimar tais modos de ser afetado. Isso nos indica que a cultura midiática não age necessariamente pelas vias de uma razão técnica/instrumental, mas antes de tudo por circuito de afectos, investindo no desejo, isto é, por uma via estética. 


\section{CONSIDERAÇÕES FINAIS}

A partir das produções da EF analisadas, se consideramos que em seu nível mais fundamental, a cultura midiática age por uma via estética, isto é, por um regime de afecções que gere o desejo dos sujeitos para determinados fins, como a busca por um padrão corporal, por exemplo; ou ainda se essa cultura midiática opera certa "pedagogia cultural" no que tange ao corpo e à saúde, há de se perguntar quais implicações esse processo pode ter para a EF? Em outros termos, consideramos ser necessário à EF (enquanto uma prática pedagógica que lida com o corpo e o movimento) pensar uma possível atitude frente aos regimes de afecções produzidas pela cultura midiática.

Acreditamos que primeiramente a questão se passa pela consideração de que a prática pedagógica da EF possa ser pensada como um circuito de afectos e em como estes podem produzir outros sujeitos distintos daqueles produzidos pela cultura midiática. Isso quer dizer que cabe à EF, em suas mediações, oportunizar aos sujeitos novas relações com o corpo e o movimento que se diferenciem das formas propagadas pela mídia, isto é, uma produção de novas subjetividades que permitam a estes sujeitos novas maneiras de serem afetados, o que não significa desconsiderar as afecções midiáticas, visto como algo impossível haja vista a onipresença da mídia e a necessidade de se identificar, analisar e refletir para saber como é essa produção para, a partir dela, ter as referências para a crítica.

Neste sentido, a EF produziria sujeitos que se relacionassem com a cultura midiática a partir de uma espécie de "heteronomia sem sujeição" (SAFATLE, 2016), isto é, um sujeito capaz de deixar-se ser afetado por aquilo que é veiculado pela mídia, mas com a condição de não limitar-se a estas afecções.

A EF, enquanto prática pedagógica, possibilitaria aos sujeitos aprender a entrar em relações de composição com o outro, com o novo, com uma nova prática corporal, por exemplo, compor-se com ela, portando a possibilidade dos sujeitos produzirem outros modos de vida, outros territórios existenciais. Isto é, os afectos produzidos a partir do encontro com essa prática pedagógica permitiria aos sujeitos ampliar sua condição de existência no sentido de produzir outras condições a partir desse aprendizado, produzindo autonomia o sujeito acaba tendo outras alternativas para viver: "agora pratico um esporte, lido com meu corpo, com a produção de saúde para além das afeç̧ões midiáticas".

\section{REFERÊNCIAS}

ALBINO, Beatriz Staimbach; VAZ, Alexandre Fernandez. Corpo e as técnicas para o embelezamento feminino: esquemas da indústria cultural na Revista Boa Forma. Movimento, Porto Alegre, v.14, n.1, p.199-223, 2008.

ARAÚJO, Alyson Carvalho; PORPINO, Karenine de Oliveira. EF e televisão: reflexões sobre sensibilidade, tecnologia e conhecimento. Pensar a Prática, Goiânia, v.10, n.2, 2007. BERGSON, Henri. Matéria e memória. São Paulo: Martins Fontes, 1990. 
BETTI, Mauro; PIRES, Giovani De Lorenzi. Verbete Mídia. In: GONZÁLES, Fernando Jaime; FENSTERSEIFER, Paulo Evaldo. Dicionário crítico de Educação Física. Ijuí: Unijuí, 2005. p. 282-288.

CHAVES, Paula Nunes; BARROS, Joyce Mariana Alvez; SOUSA, Dandara Queiroga de Oliveira; COSTA, Ana Luiza Silva; ARAÚJO, Alyson Carvalho de. Construindo diálogos entre a mídia-educação e a EF: uma experiência na escola. Motrivivência, Florianópolis, v.27, n.44, p.150-163, 2015.

DALBEN, André; SOARES, Carmen Lúcia. A Revista Vida e Saúde: modos de olhar e educar o corpo feminino em suas páginas (1940-1950). Pensar a Prática, Goiânia, v.11, n.3, p.239-250, 2008.

DELEUZE, Gilles. Espinosa: Filosofia prática. São Paulo: Escuta, 2002.

DELEUZE, Gilles. GUATTARI, Félix. O anti-Édipo: Capitalismo e esquizofrenia. Lisboa: Assírio \& Alvim, 1996.

ECO, Humberto. Como se faz uma tese. 12. ed. São Paulo: Perspectiva, 1995.

FATORELLI, Antônio. Imagem e afecção nas novas mídias. In: PARENTE, André. (org.). Cinema/Deleuze. Campinas, SP: Papirus, 2013, p.159-170.

FINCO; Mateus David; FRAGA, Alex Branco. Corpo joystick: cinema, videogames e estilo de vida ativo. Licere, Belo Horizonte, v.16, n.3, 2013.

GALAK, Eduardo et al. El concepto "cuerpo" en el campo académico de la Educación Física: un análisis a partir de la revista "Educación Física y Ciencia". In: CONGRESO ARGENTINO Y LATINOAMERICANO DE EDUCACIÓN FÍSICA Y CIENCIAS, 12;7, 2017, La Plata. Anais... La Plata: UNLP, 2017, p.1-15. Disponível em: < http:// congresoeducacionfisica.fahce.unlp.edu.ar/12o-congreso/actas-2017/Mesa 10_Galak. pdf > . Acesso em: 29 dez. 2017.

GODOI, Marcos Roberto. Corpos femininos volumosos e estética: discursos contrahegemônicos sobre beleza em blogs na internet. Movimento, Porto Alegre, v.17, n.3, p.153-173, 2011.

GOELNER, Silvana Vilodre; FIGUEIRA, Márcia Luiza Machado. Corpo e gênero: a Revista Capricho e a produção de corpos femininos. Motrivivência, Florianópolis, ano XIII, n.19, 2002.

HEROLD JUNIOR, Carlos. Corpo e educação no escotismo a partir da Revista O Tico Tico (1921-1933). Movimento, Porto Alegre, v.21, n.2, p. 303-316, 2015.

JUBÉ, Carolina Nascimento; ALMEIDA, Dulce Filgueira; FERES NETO, Alfredo. Os "avatares" do corpo rascunho: experiência de jovens universitários nas redes sociais. Licere, Belo Horizonte, v.17, n.1, p. 1-30, 2014.

LAKATOS, Eva Maria; MARCONI, Marina de Andrade. Fundamentos de metodologia científica. 3. ed. São Paulo: Atlas, 1992.

MALDONADO, Gisela De Rosso. A EF e o adolescente: a imagem corporal e a estética da transformação na mídia impressa. Mackenzie, São Paulo, v.5, n. 1, p.59-76, 2006. MORAES E SILVA, Marcelo; FONTOURA, Mariana Purcote. Educação do corpo feminino: um estudo na Revista Brasileira de Educação Física (1944-1950). Revista brasileira de EF e Esporte, São Paulo, v.25, n.2, p.263-75, 2011. 
OLIVEIRA, Alexandre Palma de; ASSIS, Monique; LACERDA, Yara; BAGRICHEVSKY, Marcos; SAMPAIO, Karen Santana de Sampaio. Culto ao corpo e exposição de produtos na mídia especializada em estética e saúde. Movimento, Porto Alegre, v.16, n.1, p.31-51, 2010.

PINTO, Fabio Machado; PEREIRA, Lana Gomes. A experiência de ver filmes na formação inicial de professores de EF. Pensar a Prática, Goiânia, 8/1, p.101-115, 2005.

PINTO, Sayonara Carla; GOMES, Ivan Marcelo; ALMEIDA, Felipe Quintão de; MORAES, Cláudia Emilia; ALMEIDA, Ludmila Santos. Identidade(s) feminina(s) e cuidado de si na Revista AG. Motrivivência, Florianópolis, ano XXIV, n.39, p.113-128, 2012.

SAFATLE, Vladimir. O circuito dos afetos: Corpos políticos, desamparo e o fim do indivíduo. Belo Horizonte: Autêntica, 2016.

SHAVIRO, Steven. O corpo cinemático. São Paulo: Paullus, 2015.

SALVINI, Leila; MYSKYW, Mauro. Representação do corpo feminino na Revista Claudia no ano de 2006: retrato de uma produção restrita. Revista da UEM, Maringá, v.19, n. 4, p. 521-528, 2008.

SILVA, Cíntia Vieira da. Corpo e pensamento: Alianças conceituais entre Deleuze e Espinosa. Campinas: Unicamp, 2013.

SILVA, Cecília Nunes Silva; GOMES, Ivan Marcelo; ALMEIDA, Felipe Quintão de. Beleza e feminilidade: o corpo feminino nas páginas da Revista Vida Capichaba (1925-1939). Motrivivência, Florianópolis, v.27, n.46, p.35-52, 2015.

SOUZA, Daniel Minuzzi de. Cultura corporal na pauta do jornal: notas de uma análise a partir do Programa AN Escola". Motrivivência, Florianópolis, ano XXII, n.35, p.247263, 2010.

THOMPSON, John Brookshire. A mídia e a modernidade: uma teoria social da mídia. 8ª. ed. Petrópolis: Vozes, 1998.

VENDRUSCOLO, Mayra Fernanda; MALINA, André; AZEVEDO; Ângela Celeste Barreto de. A concepção de obesidade e padrão corporal por mediações ideológicas da mídia. Pensar a Prática, Goiânia, v.17, n.2, p. 503-516, 2014.

Recebido em: Outubro/2017 Aprovado em: Janeiro/2018 